\title{
Short tarsus-absence of lower eyelashes syndrome
}

INSERM

\section{Source}

INSERM. (1999). Orphanet: an online rare disease and orphan drug data base. Short tarsus-absence of lower eyelashes syndrome. ORPHA:2832

Short tarsus - absence of lower eyelashes is a very rare syndrome characterized by the association of thin and short upper and lower tarsus and absence of the lower eyelashes. 